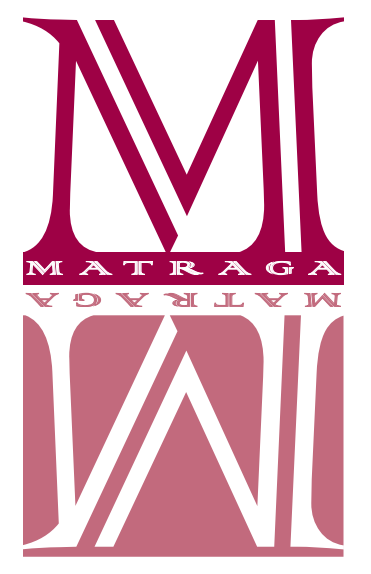

\title{
A articulação de estruturas sintáticas como fio condutor para a construção do(s) sentido(s) do texto
}

\author{
Keyla Silva Rabêlo \\ Universidade do Estado do Rio de Janeiro \\ https://orcid.org/0000-0002-1970-1697
}

\begin{abstract}
RESUMO
A proposta deste trabalho é apresentar uma análise de texto baseada em procedimentos formais da sintaxe a serviço da estruturação do significado textual. Como corpus de análise, foi selecionado um texto publicado em 2016 em um portal virtual de notícias. Na análise de dados, apoiamo-nos, principalmente, em discussões realizadas no âmbito das Teorias do Texto (GERALDI, 1997; KOCH, 2010) e das Teorias Gramaticais (AZEREDO, 2010; NEVES, 2016). Os resultados apontam para a importância de um trabalho com gramática que leve o sujeito à tomada de consciência dos recursos disponíveis na língua - sintáticos, lexicais, semânticos - a fim de que possa usá-los como ferramenta para o desenvolvimento de sua capacidade crítico-reflexiva em relação às questões de leitura, produção e compreensão de texto.
\end{abstract}

PALAVRAS-CHAVE: Análise textual; Sintaxe; Escrita

\section{The Articulation of Syntactic Structures as a Conductor Wire for The Construction of The Meaning(s) of The Text}

\section{ABSTRACT}

The proposal of this work is to present a text analysis based on formal syntax procedures at the service of the structuring of textual significance. As corpus of analysis, a text published in 2016 in a virtual news portal was selected. In the analysis of data, we support mainly in discussions carried out in the context of Textual (GERALDI, 1997; KOCH, 2010) and Grammatical theories (AZEREDO, 2010; NEVES, 2016). The results point to the importance of a grammar work that leads the subject to the awareness of the resources - syntactic, lexical, semantic - available in the language so that one can use them as a tool for the development of his critical-reflective capacity in relation to reading, production and comprehension of text issues.

KEYWORDS: Textual analysis. Syntax. Writing 


\section{Introdução}

A linguagem, em suas diversas manifestações (sonora, imagética, verbal, oral, gestual), possibilita-nos interagir de forma participativa e crítica em relação à dinâmica social na qual estamos inseridos e estas são estratégias que utilizamos para lidar com o mundo, reconhecendo-o na sua pluralidade de demanda já que, conforme aponta Rabêlo (2014, p. 17), aceitar, questionar e desafiar as formas de conhecimento vincula-se aos diferentes textos que usamos nas mais diversas circunstâncias de interação.

Azeredo (1999, p. 245) aponta que essa transfiguração da experiência do mundo pela linguagem, que constitui o discurso, é um percurso de criação de sentido no qual o enunciador se move administrando pelo menos cinco ordens de fatores:

a) o assunto sobre o qual vai discorrer;

b) o conjunto de crenças, convicções, opiniões, etc. que tem sobre a posição desse assunto na esfera sociocultural a que ele - enunciador - pertence;

c) o projeto de sentido - que está aliado aos efeitos comunicativos que pretende produzir;

d) os modos de organização do discurso, e

e) o sistema de meios gramaticais e textuais da língua.

Esses fatores apresentam uma opção fundamental por uma teoria da linguagem que a considere em sua dimensão discursiva. Nesse sentido, Geraldi (1997) traz a seguinte reflexão:

[...] a linguagem não se dá como objeto epistemológico. Dá-se por inteiro, em sua dimensão política, histórica, social, contextual. Dá-se como um acontecimento interativo e multifacetado, estruturante mais do que estrutura. Envolve, pois, ações: além da ação que a linguagem, ela mesma, é, as ações que a linguagem faz e as ações que com ela se faz e que se fazem sobre ela. (GERALDI 1997, p. 11-12)

O presente artigo, dessa forma, objetiva apresentar uma atividade de operação sobre a linguagem a partir da análise de texto baseada em procedimentos formais da sintaxe a serviço da estruturação do significado textual. Nas palavras de Guimarães (1999 p. 131), por meio de exercícios como o que aqui propomos, pode-se "apreender a articulação das estruturas sintáticas, bem como as diversas funções exercidas pelos termos que constituem tais estruturas" e "recuperar no estudo de aspectos gramaticais a dimensão da língua em funcionamento". O texto analisado é uma notícia - Como redescobri, sem querer, pássaro de olhos azuis desaparecido no Brasil havia 75 anos $^{1}$ - publicada em 2016 pela jornalista uruguaia Alejandra Martins, correspondente BBC Mundo no portal de notícias UOL. A perspectiva teórica adotada para análise do corpus está amparada nas discussões sobre as Teorias do texto e Teorias gramaticais.

\footnotetext{
1 Texto na íntegra disponível em: https://www.bbc.com/portuguese/geral-36486123\#: :text=V\%C3\%ADdeos-,'Como\%20 redescobri\%2C\%20sem $\% 20$ querer $\% 2$ C $\% 20$ p $\%$ C3\%A1ssaro\%20de $\% 20$ olhos $\% 20$ azuis $\% 20$ desaparecido,no $\% 20$ Brasil $\% 20$ havia\%2075\%20anos'\&text=Uma\%20esp\%C3\%A9cie\%20rara\%20de\%20ave,n\%C3\%A30\%20era\%20avistada $\% 20$ na $\% 20$ natureza. Acesso em: 15 fev. 2020.
} 


\title{
2. Algumas considerações sobre língua, texto e gramática
}

As línguas, conforme nos indica Azeredo (1999 p. 245), são formas de conhecimento coletivamente constituídas no seio das sociedades ao longo de sua experiência histórica. Conhecer a língua significa tão somente estar apto a servir-se dela para tomar parte na rotina social da comunidade (AZEREDO, 2013 p. 22).

Semelhante posicionamento apresenta Ianni (1999) ao dizer que

\begin{abstract}
A língua é, simultaneamente, produto e condição da vida social. Os trabalhos e os dias de uns e outros, indivíduos e coletividades, ao longo da história, propiciam a criação e a recriação de signos e significados, figuras e figurações, harmonias e cacofonias, monólogos e polifonias, sem os quais não existem nem as formas de sociabilidade nem a língua. O mesmo processo de produção e reprodução da vida social compreende a produção e reprodução das coisas, gentes e ideias, toda uma multiplicidade de signos e significados, transparências e opacidades, sonoridades e estridências. (IANNI, 1999 p. 13)
\end{abstract}

A língua, dessa forma, apresenta-se como uma construção social, histórica, cultural e ideológica, configurando-se, portanto, como instrumento de poder. Ao tempo em que se coloca como obstáculo, como limitadora, também é passagem, libertação. É ela quem habilita o indivíduo a resistir aos processos de dominação.

O discurso, por sua vez, constitui-se por meio dessas construções e dos conhecimentos histórico-sociais das experiências de vida dos indivíduos e das coletividades. Nesse movimento - língua e discurso -, textos são produzidos em múltiplas linguagens, circulam, carregam informações diversas e produzem sentido(s) através da interação verbal locutor / interlocutores. Esse processo de interação, segundo Charaudeau (1992 apud Azeredo 1999, p. 246), baseia-se num contrato de comunicação que diz respeito às convenções sobre os vários tipos de textos adequados à natureza da interação e aos propósitos comunicativos que envolvem o enunciador e o destinatário.

Azeredo (2013) argumenta que

os sentidos que circulam por meio de nossos discursos não estão alojados na mente do enunciador como entidades abstratas à espera de que as palavras os captem e os tornem acessíveis ao ouvinte ou leitor. Esses sentidos 'só ganham vida' de fato quando são objetivados no discurso mediante a seleção das unidades léxicas e os diversos procedimentos gramaticais necessários à textualização delas. (AZEREDO, 2013 p. 25)

Considera-se, portanto, o texto como uma rede onde as relações entre as categorias gramaticais - fonética e fonologia, morfologia, sintaxe, estilística - atuam de forma combinatória. Essas categorias e a forma das unidades, de acordo com Azeredo (2012, p. 123), não são livremente selecionadas. $\mathrm{O}$ autor indica que

A construção do texto está assim sujeita a fatores combinatórios que tanto especificam as categorias/classes e formas das unidades que o constituem, quanto impõem limites ao posicionamento dessas unidades. Noutras palavras, o texto se realiza por meio de uma construção formal, sem a 
qual o sentido seria impossível. Esta construção formal, por sua vez, baseia-se no sistema de unidades e regras combinatórias a que damos o nome de gramática (...). (AZEREDO, 2012 p. 124)

Como vemos, "a gramática é responsável, portanto, por uma parte do significado dos enunciados - aquele que resulta dos meios pelos quais as unidades portadoras de significado se combinam para construir as frases". (AZEREDO, 2012 p. 125)

As discussões sobre língua, discurso, texto e gramática apresentadas até aqui servirão como eixo teórico orientador para a análise textual que será apresentada na seção a seguir, cujo objetivo é estudar os aspectos gramaticais presentes no texto escolhido como corpus de análise a fim de apropriar-nos de mecanismos que possibilitem a observação da dimensão da língua em funcionamento.

\section{A análise textual}

O texto tomado para análise configura-se como um texto noticioso que, conforme explicita Costa (2012, p.179-180), se configura como um relato ou narrativa de fatos, acontecimentos, informações, recentes ou atuais, do cotidiano, ocorridos na cidade, no campo, no país ou no mundo.

Seu título - Como redescobri, sem querer, pássaro de olhos azuis desaparecido no Brasil havia 75 anos - foge da formatação comumente adotada por esse tipo de texto ao incorporar, em sua composição, uma citação. Azeredo (2012, p. 97) indica que o uso da transposição direta na citação consiste em dar a palavra ao personagem da cena enunciativa. Essa estratégia, marcada aí pelo emprego das aspas como procedimento gráfico, apresenta finalidades discursivas variadas como conferir credibilidade ao que se diz/ escreve (AZEREDO, 2012, p. 96).

Como vemos, o sujeito gramatical que assume a voz, neste espaço, está indicado pelo morfema $-i$ (Redescobr- $i$ ), indicador, nos verbos, da $1^{\text {a }}$ pessoa do singular no pretérito perfeito do indicativo. Escolher um pronome, ainda que designado pelo verbo, para desempenhar o papel semântico de agente do processo em vez de uma expressão substantiva pode indicar as intenções do autor do texto: ocultar, em um primeiro momento, a identidade daquele a quem foi, ali, conferida a fala e justificar a ocorrência de um encontro despretensioso entre um especialista em aves e uma espécie rara de pássaro. A raridade do pássaro é especificada distintivamente pela locução adjetiva "de olhos azuis" e pelo uso da forma nominal (particípio) do verbo desaparecer (desaparecido) que atua semelhante a um adjetivo. É importante destacar que a casualidade do achado é indicada pela presença da expressão "sem querer" que funciona como um adjunto adverbial focalizador, cuja função consiste em "particularizar uma informação em nome de um propósito argumentativo ou enfático do enunciador" (AZEREDO, 2012 p. 283).

O primeiro parágrafo tem como pano de fundo a preparação do leitor em relação ao assunto que será tratado no texto e dialoga com a expectativa já criada no título ("pássaro de olhos azuis" = "Uma espécie rara de ave"; redescoberta "sem querer" = "encontro fortuito" e "no Brasil" = "no interior de Minas Gerais"). Encontramos neste parágrafo uma síntese dos fatos 
(a redescoberta, no Brasil, de um pássaro raro), a identificação das pessoas (um ornitólogo brasileiro) e de lugares (o fato ocorreu no interior de Minas Gerais) e o destaque do ponto peculiar da história (mesmo que a redescoberta tenha sido realizada pelo ornitólogo, um especialista em aves, o encontro ocorreu de forma casual). Este tipo de construção configura-se, de acordo com Costa (2012, p. 159-160), como lide, técnica de gancho mais usada na redação de notícias.

De forma geral, o texto é dividido em três partes: I) parte introdutória na qual o autor narra com detalhes como se deu a redescoberta desta ave pelo pesquisador Rafael Bessa; II) com o subtítulo "Raridade", esta parte traz informações sobre a época e o local em que a ave havia sido avistada pela última vez, fatores que contribuíram para sua raridade e a quantidade de espécies avistadas após o primeiro reencontro e III) intitulada por “Conservação”, esta seção indica a necessidade de se traçar um plano de conservação da espécie, critica a forma como tratamos nossa biodiversidade e as tentativas de fragilização de nossa legislação ambiental para favorecer a criação de empreendimentos comerciais.

O texto relata uma situação em que seus enunciados contêm, em sua maioria, verbos no pretérito perfeito e no pretérito imperfeito do modo indicativo: "Uma espécie rara de ave que cientistas 'consideravam' extinta..." (Linha 1); “'Há' 75 anos, a ave não 'era avistada' na natureza” (Linha 3); "Bessa 'voltou' ao local no dia seguinte..." (Linha 12); “'Olhei' pelo Binóculo, e minhas pernas 'começaram' a tremer..."(Linha 15) etc. Essa ocorrência é muito maior nas duas primeiras partes do texto - apresentação do fato ocorrido (a redescoberta da ave) e o porquê da raridade da ave e suas principais características - por nelas encontrarmos enunciados que se configuram como narração do episódio ocorrido e, também, apresentação da fala do pesquisador sobre a experiência vivenciada marcada, como já mencionado em outro momento, pelo recurso gráfico das aspas.

Já na terceira parte, o ponto de referência é marcado pelo próprio momento da enunciação. Nesta seção, o locutor situa seu interlocutor sobre como a situação narrada se encontra (o que se deseja fazer pós redescoberta da ave, quais estratégias serão adotadas para a conservação da espécie etc,). Essa temporalidade é marca por verbos no presente: "Agora cientistas 'trabalham' para traçar planos de conservação" (Linha 38); "No momento, sabemos da existência de 12 exemplares...” (Linha 44); “O ornitólogo 'diz' que a redescoberta...” (Linha 47); “Existem' ainda pelo menos uma dezena de espécies que 'estão desaparecidas'..." (Linha 50); "Ele 'faz' críticas..." (Linha 52). O advérbio "agora” - “Agora, cientistas trabalham para traçar planos...” (Linha38) - e a expressão adverbial "no momento"- "No momento', sabemos da existência de 12 exemplares..." (Linha 44) - indicam o marco temporal básico do falante, atuando como elementos dêiticos. A representação do tempo como categoria da linguagem verbal é, segundo Azeredo (2010, p. 204), parte dessa atividade discursiva, que tem no momento da enunciação (ME) seu ponto de referência principal.

É interessante observarmos, no texto, algumas estratégias referenciais utilizadas pelo enunciador em seu projeto de dizer. Trata-se, segundo Koch (2010, p. 131), "de estratégias por meio das quais são construídos os objetos-de-discurso e mantidos ou focalizados na pluralidade do texto". 
Sobre o assunto, Neves acrescenta:

No processo da língua em uso, os participantes de um discurso negociam o universo de discurso de que falam, e, dentro dele, num determinado momento, escolhem referir-se a algum (alguns) indivíduo(s) cuja identidade estabelecem - ou não - garantir a sua existência nesse universo. Isso significa que referenciação envolve interação e, consequentemente, intenção (NEVES, 2016, p. 75)

Como supõe Neves, essas escolhas não ocorrem de forma aleatória, mas de acordo com os propósitos comunicativos do sujeito "que constrói seus enunciados conferindo relevância aos argumentos seguindo o que seja conveniente a esses propósitos" (NEVES, 2016, p. 80).

Observemos, então, o parágrafo inicial do texto:

QUADRO 1. Introdução de referente

"Uma espécie rara de ave" que cientistas consideravam extinta foi redescoberta graças a um encontro fortuito entre um ornitólogo e "o pássaro" do interior de Minas Gerais.

Fonte: Produzido pela autora

Há, aí, a introdução do referente representado pela expressão nominal "Uma espécie rara de ave". Como foi introduzido no texto um objeto de discurso totalmente novo, diz-se que ocorreu uma introdução não-ancorada. No mesmo parágrafo, este referente é retomado através da expressão nominal “o pássaro”. A autora, neste parágrafo, utiliza como estratégia de recuperação do referente uma forma nominal, o que, por efeito, acaba promovendo sua recategorização.

Neves (2016, p. 100) entende que cada expressão referencial nominal é uma categorização, isto é, uma colocação do referente em determinada categoria cognitivamente estabelecida.

Várias são as maneiras de reapresentação de referentes (formas de valor pronominal, numerais, certos advérbios locativos, elipses e formas nominais) e elas podem ocorrer em dois movimentos - de forma retrospectiva ou de forma prospectiva -, contribuindo, assim, para a progressão referencial do texto.

Com base nos elementos linguísticos apresentados por Koch $(2010,2016)$ no processo de retomada de referentes, construímos, a seguir, um quadro na tentativa de identificar os elementos linguísticos utilizados para retomar, ao longo do texto, o referente "Uma espécie rara de ave":

QUADRO 2. Elementos linguísticos utilizados para retomada de referente

\begin{tabular}{|l|l|}
\hline PRONOMINALIZAÇÃO & $\emptyset$ \\
\hline NUMERAIS & $\begin{array}{l}\bullet \text { "0 primeiro exemplar" (linha 31); } \\
\bullet 12 \text { exemplinhas-do-planalto" (linha 31); (linha 44); } \\
\bullet \text { "Os únicos 12 indivíduos" (linha 55) }\end{array}$ \\
\hline ADVÉRBIOS LOCATIVOS & $\emptyset$ \\
\hline
\end{tabular}

(continua) 
(continuação)

\begin{tabular}{|c|c|}
\hline ELIPSES & $\begin{array}{l}\text { - "que pousou [um pássaro] em um arbusto" (linha 13) } \\
\text { - "e dificilmente era avistada [uma espécie rara]..." (linhas 22-23) } \\
\text { - "e [a ave] é bem menor do que outras rolinhas" (linhas 34-35) } \\
\text { - "a área onde [a espécie] foi encontrada" (linha 39) } \\
\text { - "seu canto [dos espécimes]" (linha 41) } \\
\text { - "e que correm [ as espécies] o risco de serem extintas" (linha 51); }\end{array}$ \\
\hline FORMAS NOMINAIS & 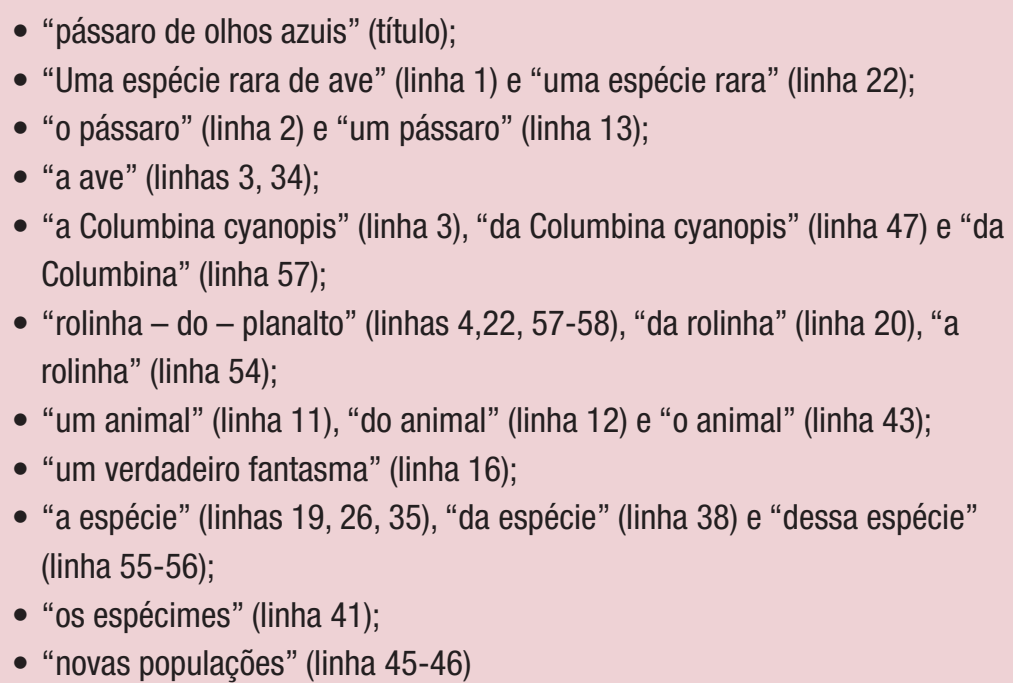 \\
\hline
\end{tabular}

Nota do Quadro 2: Na contagem de linhas, considerei os títulos das seções que compõem o texto ("Raridade" e “Conservação").

Nota-se que há uma predominância do emprego de formas ou expressões nominais referenciais ao longo do texto. Elas, além de efetivarem a progressão textual, desempenham, conforme aponta Koch (2010, p. 148), funções importantes para a construção de sentidos no texto, A seguir, exemplificarei algumas dessas funções identificadas no texto que estamos analisando:

- Apresentar e reapresentar o referente à medida que o texto avança:

\section{EXEMPL0 1}

QUADRO 3. Apresentação/ Reapresentação de referente

"Uma espécie rara de ave" que cientistas consideravam extinta foi redescoberta graças a um encontro fortuito entre "um ornitólogo brasileiro" e "o pássaro" no interior de Minas Gerais.

Há 75 anos, a ave não era avistada na natureza. Desde 1941, "a Columbina cyanopis", ou "rolinha-doplanalto", como é chamada no Brasil, só podia ser apreciada por meio de espécimes preservadas em museus.

Isso começou a mudar depois de um lance de sorte vivido "pelo ornitólogo Rafael Bessa", que, em julho de 2015, estava em uma região do interior mineiro (que está sendo mantida em segredo por razões explicadas mais abaixo) para fazer um levantamento.

"0 pesquisador" havia decidido pegar um atalho no caminho entre seu hotel e o local onde realizaria seu trabalho.

Fonte: Produzido pela autora 
No exemplo 1, vemos a introdução do referente "Uma espécie rara de ave". Ele é caracterizado como um sintagma referencial indefinido específico e indicado pela presença do artigo indefinido "um". Segundo Neves (2016, p. 126), esse tipo de sintagma implica a existência de algum indivíduo que satisfaz a descrição, ou seja, dentre as diversas espécies de aves, há uma que é rara, que se encontra em extinção. Esse mesmo referente fica em evidência retomado por meio de sintagmas nominais definidos marcados, nestes casos, pela presença do artigo definido antecedendo o substantivo ("o pássaro" e "a Columbina cyanopis"). Neves (2016) explica que, em se tratando do uso do sintagma nominal definido, o falante/escritor aposta que seu interlocutor "reconhecerá na situação discursiva (ou no conhecimento compartilhado) a descrição a que ele se refere" (p. 124), principalmente quando esse referente já foi mencionado e é facilmente identificado pela memória desse interlocutor. Nesse sentido, quando o leitor do texto que estamos analisando se depara com as expressões "o pássaro" e "a Columbina cyanopis", ele está sendo instruído a remeter a ideia que esses objetos ativam em sua memória ao referente "Uma espécie rara de ave" e a ação se dá de forma bem-sucedida. Nesse período, mantendo o referente em evidência, encontramos, ainda, o emprego do sintagma nominal "rolinha-do-planalto". Esse termo, ligado à expressão que o antecede "a Columbina cyanopis" através da conjunção coordenativa alternativa "ou", orienta o leitor a compreender que essa espécie pode ser conhecida tanto por seu nome científico quanto por seu nome popular.

Nesse movimento textual, ocorre a introdução de outro referente "um ornitólogo brasileiro", retomado pelos sintagmas nominais "pelo ornitólogo Rafael Bessa" e "O pesquisador". O escritor do texto usa as mesmas estratégias descritas anteriormente: o referente é construído por um sintagma referencial indefinido específico e retomado por meio de sintagmas nominais definidos. Nas duas situações, as formas nominais contribuem para a ativação da memória textual dos leitores e possibilitam a manutenção da cadeia semântica do texto.

- Categorizar e recategorizar o referente

A fim de garantir, ao longo do texto, a recuperação do referente "Uma espécie rara de ave", foram utilizadas formas nominais com as mesmas características e propriedades do objeto designado, ora de forma específica ("o pássaro", "a ave”) ora de forma mais genérica ("os espécimes", "novas populações"). Há, entretanto, um momento em que a recategorização desse objeto teve sua predicação enfaticamente marcada pela avaliação do produtor do texto, como observamos no exemplo a seguir:

\section{EXEMPLO 2}

QUADRO 4. Categorização e Recategorização de referente

Bessa voltou ao local no dia seguinte para registrar o canto do animal e, ao reproduzir a gravação, atraiu em sua direção um pássaro, que pousou em um arbusto a alguns metros de distância.

"Olhei pelo binóculo, e minhas pernas começaram a tremer. Sabia que tinha "um verdadeiro fantasma" na minha frente. Foi um momento de muita emoção, indescritível. Estava muito feliz e nervoso ao mesmo tempo", diz Bessa 
A utilização da expressão nominal "um verdadeiro fantasma" direciona argumentativamente o leitor para o objetivo do texto: apresentar a redescoberta de uma espécie de ave desaparecida há quase oito décadas, fato que reforça a crença em sua extinção.

Isso acontece porque "a avaliação do falante em relação ao objeto designado tem papel muito significativo na condução argumentativa do enunciado, servindo a seus propósitos, suas opiniões e suas crenças, e direcionando as (re)designações, para a eficiência da atuação linguística”. (NEVES, 2016, p. 120)

- Marcar o parágrafo (cognitivamente)

Koch $(2010,2016)$ e Neves (2016) falam sobre a importância das formas nominais na função textual e como isso fica, sob uma ótica cognitivista, evidenciado na marcação dos parágrafos. Analisemos o fragmento a seguir:

\section{EXEMPLO 3}

QUADRO 5. Marcação do parágrafo

"Uma espécie rara de ave" que cientistas consideravam extinta foi redescoberta graças a um encontro fortuito entre "um ornitólogo brasileiro" e "o pássaro" no interior de Minas Gerais. Há 75 anos, "a ave" não era avistada na natureza. Desde 1941, "a Columbina cyanopis", ou "rolinha-do-planalto", como é chamada no Brasil, só podia ser apreciada por meio de espécimes preservadas em museus.

Isso começou a mudar depois de um lance de sorte vivido "pelo ornitólogo Rafael Bessa", que, em julho de 2015, estava em uma região do interior mineiro (que está sendo mantida em segredo por razões explicadas mais abaixo) para fazer um levantamento.

"0 pesquisador" havia decidido pegar um atalho no caminho entre seu hotel e o local onde realizaria seu trabalho. Na rota, decidiu parar em um certo ponto para apreciar e fotografar a vista. Foi quando ouviu sons de um animal que não reconheceu. "Bessa" voltou ao local no dia seguinte para registrar o canto do animal e, ao reproduzir a gravação, atraiu em sua direção um pássaro, que pousou em um arbusto a alguns metros de distância.

Fonte: Produzido pela autora

Um referente é introduzido (Uma espécie rara de ave) e conduz o leitor ao entendimento do assunto que será abordado no parágrafo. Este referente é retomado no mesmo parágrafo (o pássaro) e no início do parágrafo seguinte (a ave) a fim de efetivar sua permanência na memória do leitor, uma vez que um novo referente é introduzido (um ornitólogo brasileiro) e é deixado em stand by, só retomado mais adiante ("O pesquisador" e "Bessa") com o pretexto de explicar como a situação ocorreu e validar o fato.

Como vimos, a disposição das formas nominais nesta primeira parte contribui para a organização do texto: primeiro, situa o leitor quanto ao fato ocorrido e, depois, indica-lhe como tudo ocorreu.

Koch ainda chama atenção para o fato de o referente ser "resultado de encapsulamento de um segmento textual e, nesse caso, se apresenta sob a forma de um rótulo" (2016, p. 95). Na notícia analisada não foi identificada nenhuma ocorrência de resumo ou encapsulamento de porções 
textuais através de formas nominais, entretanto o uso do pronome demonstrativo como uma construção dêitica e remissiva:

\section{EXEMPLO 4}

QUADRO 6. Construção dêitica remissiva

Há 75 anos, a ave não era avistada na natureza. Desde 1941, a Columbina cyanopis, ou rolinha-do-planalto, como é chamada no Brasil, só podia ser apreciada por meio de espécimes preservadas em museus.

"Isso" começou a mudar depois de um lance de sorte vivido pelo ornitólogo Rafael Bessa, que, em julho de 2015, estava em uma região do interior mineiro (que está sendo mantida em segredo por razões explicadas mais abaixo) para fazer um levantamento.

Fonte: Produzido pela autora

Nota-se que o pronome "isso" condensa a informação contida no parágrafo anterior (só podia ser apreciada por meio de espécimes preservadas em museus). Segundo Azeredo (2012, p. 248), esse tipo de construção é possível porque "os pronomes demonstrativos servem para localizar, em relação às pessoas do discurso, os objetos (seres, coisas e noções) que entram no conteúdo de nossos enunciados", operando, no caso texto escrito, "no próprio texto em construção" por ser esse um "espaço de comunicação em que prevalece a função anafórica ou remissiva dos demonstrativos".

Outra questão que chama atenção no texto é a presença de verbos na voz passiva. A voz - forma especial em que se apresenta o verbo (BECHARA, 2015, p. 235) - é uma categoria gramatical responsável em atribuir ao sujeito uma função. No caso da voz passiva, como podemos perceber nos exemplos a seguir, o sujeito é, necessariamente, um ser afetado pelo processo indicado no verbo:

“'Uma espécie rara de ave’ [sujeito paciente] que cientistas consideravam extinta foi redescoberta...” (Linha 1 )

“Desde que 'o primeiro exemplar' [sujeito paciente] foi identificado por Bessa, 12 rolinhas-do-planalto [sujeito paciente] foram ao todo avistadas por pesquisadores..." (linhas 31-32)

As decisões dos enunciados são propiciadas através da construção verbal escolhida para a enunciação. Em se tratando de voz passiva, Azeredo (2012, p. 274) indica que a construção passiva realça o paciente e permite a omissão do agente. Podemos observar essa situação nos exemplos a seguir:

"Há 75 anos, a ave não 'era avistada’ na natureza" (Linha 3)

“(...) o local onde os espécimes 'foram achados' e seu canto não serão divulgados...” (Linhas 41-42) 
Os enunciados trazidos como exemplo ilustram a formação típica da voz passiva (AZEREDO 2012, p. 274), constituída pelo verbo auxiliar (consideravam, foram, era) seguido do particípio do verbo principal (extinta, identificado, avistada, achados). Uma outra possibilidade de construção seria indeterminar o agente do processo verbal:

“Até então, não se entendia o porquê dessa raridade..." (Linha 25)

Sobre o uso do particípio em algumas construções, Azeredo (2012) explica:

O particípio é uma forma eminentemente verbal, quando, invariável, vem precedido do verbo auxiliar "ter/haver" na formação dos chamados tempos compostos. Quando, porém, é variável em gênero e número - como na construção passiva (as cartas foram enviadas) - o particípio se aproxima dos adjetivos, de tal sorte que, em muitos casos, migra para esta classe (cf. calado em uma criança calada; preparado em funcionários preparados; salgado em comida salgada). (AZEREDO, 2012, p. 347)

Os fragmentos abaixo ilustram essa caracterização do particípio aproximando-se do adjetivo em construções passivas:

"Bessa explica que a rolinha-do-planalto sempre 'foi considerada' uma espécie rara e dificilmente era avistada mesmo quando seu habitat, o cerrado brasileiro, ainda 'era' bastante 'preservado', até meados da década de 1950”. (Linhas 22-25)

“Existem ainda pelo menos uma dezena de espécies que 'estão desaparecidas' há mais de dez anos e que correm o risco de 'serem extintas' em um curto espaço de tempo" (Linhas 50-51)

Como se viu ao longo destas análises, inúmeros são os recursos linguísticos que temos disponíveis para lidar com a construção dos sentidos do texto. O que houve, aqui, foi apenas uma tentativa de demonstrar algumas dessas possibilidades.

\section{Considerações finais}

Muitas são as reflexões que precisam ser realizadas sobre a linguagem e sobre seu funcionamento a fim de que as propostas de educação linguística a serem desenvolvidas na escola possam, de fato, promover a consciência crítica dos falantes em relação ao uso dos recursos que temos disponíveis na língua. A escola não deve, pois, temer a presença do texto na sala de aula, uma vez que ele possibilita vivências reais da prática de linguagem. Trata-se, fundamentalmente, de fornecer aos alunos os instrumentos necessários para que eles possam progredir e agir de forma autônoma sobre a linguagem.

Sobre a importância do trabalho de linguagem com o texto, Pereira (1999) diz:

um texto é a língua portuguesa concretizada, viva, atual, plena. Traduz o que viemos acumulando em relação a teorias e conceitos, exemplarmente construído, trabalhado, operacionalizado. Não importa se de modo convencional ou não. Tudo são possibilidades idiomáticas. (PEREIRA, 1999, p. 221) 
Segundo Azeredo (2013, p. 39), as palavras e as construções sintáticas são formas potencialmente significativas armazenadas na memória de seus usuários, mas é no ato interativo socialmente situado que os sentidos que de fato interessam são gerados/percebidos/trocados como discurso e a forma de textos. Acrescenta ainda (AZEREDO, 2013, p. 40) que o trabalho com gramática deve ter por objetivo o desenvolvimento de uma técnica de descoberta e de tomada de consciência dos recursos estruturantes dos enunciados e dos textos que aguce a sensibilidade linguística do estudante.

Em conformidade com essa expectativa, neste trabalho, os resultados da proposta de análise de texto demostraram o quanto a compreensão dos aspectos gramaticais instrumentaliza os sujeitos usuários da língua a recorrerem a vários critérios avaliativos para a articulação e organização textual, além propiciar que esses sujeitos se sirvam da operacionalização destes elementos para a compreensão dos possíveis sentidos dos textos.

\section{REFERÊNCIAS}

AZEREDO, José Carlos de. Gramática Houaiss de Língua Portuguesa. São Paulo: Publifolha, 2012. A análise gramatical e a explicação de textos. Caderno de Letras da UFF. Niterói, RJ, v. 23, n. 46, p. 21-41, 2013.

.Aspectos semântico-textuais do nome e da nominalização. In: VALENTE, André (Org.). Aula de português: perspectivas inovadoras. Petrópolis, RJ: Vozes, 1999. p. 245-256.

BECHARA, Evanildo. Moderna Gramática Portuguesa. 38. Ed.rev.ampl. Rio de Janeiro: Nova Fronteira, 2015.

COSTA, S. Roberto. Dicionário de gêneros textuais. 3. ed. Belo Horizonte: Autêntica, 2012.

GERALDI, J. W. Portos de passagem. 4. ed. São Paulo: Martins Fontes, 1997.

GUIMARÃES, Elisa. Sintaxe e coesão no texto. In: VALENTE, André (Org.). Aula de português: perspectivas inovadoras. Petrópolis, RJ: Vozes, 1999. p. 129-136.

IANNI, Octavio. Língua e sociedade. In: VALENTE, André (Org.). Aula de português: perspectivas inovadoras. Petrópolis, RJ: Vozes, 1999. p. 11-47.

KOCH, I. G. V.; ELIAS, M. V. Ler e escrever: estratégias de produção textual. 2. ed. São Paulo: Contexto, 2010. Escrever e argumentar. São Paulo: Contexto, 2016.

NEVES, Maria Helena de Moura. Texto e gramática. 2. ed., 1ª reimpressão. - São Paulo: Contexto, 2016.

PEREIRA, M.T.G. Língua portuguesa: da sua celebração em forma de textos. In: VALENTE, André (Org.). Aula de português: perspectivas inovadoras. Petrópolis, RJ: Vozes, 1999. p. 217-234.

RABÊLO, Keyla Silva. A arquitetura das políticas de escrita na escola: portas-onde ou portas-contra? / Keyla Silva Rabêlo. - 2014. 138 f. (Dissertação (Mestrado) - Universidade Federal da Bahia. Faculdade de Educação, Salvador, 2014) 